\title{
The effect of aerobic training and resveratrol on some regulatory and executive factors of cardiomyocytes apoptosis in STZ-diabetic male rats
}

\author{
Ali Mehri ${ }^{1}$ Sedigheh Hosseinpour Delaware ${ }^{2}$, Masoume Azizi $^{3}$, Mohammad Ali Azarbaijani ${ }^{4}$, Parvin Farzangi ${ }^{5}$ \\ ${ }^{1}$ PhD Candidate of Sport Physiology, Kermanshah Branch, Islamic Azad University, Kermanshah, Iran \\ 2 Assistant Professor, Department of Physical Education and Sport Science, Kermanshah Branch Islamic Azad \\ University, Kermanshah, Iran \\ ${ }^{3}$ Assistant Professor, Department of Physical Education and Sport Sciences, Abadan Branch, Islamic Azad University, \\ Abadan, Iran \\ ${ }^{4}$ Professor, Faculty of Physical Education and Sport Sciences, Islamic Azad University, Tehran Branch, Tehran, Iran \\ ${ }^{5}$ Associate Professor, Department of Physiology, Islamic Azad University, Sari Branch, Sari, Iran
}

\begin{abstract}
Background: The present study was conducted to investigate the effect of aerobic training with resveratrol supplementation on regulatory and executive factors of cardiomyocytes apoptosis in streptozocin diabetic male rats.

Materials and methods: In an experimental study, 50 male rats were randomly divided into 5 groups of 10 healthy controls, diabetics, resveratrol supplements, aerobic training and complementary resveratrol + aerobic training. Diabetes was induced by single injection of streptozotocin $(50 \mathrm{ml} / \mathrm{kg})$. Training was done 5 days per week for 8 weeks. They did exercise on the treadmill at $15 \mathrm{~m} / \mathrm{min}, 5 \mathrm{~min}$ and gradient of $15 \%$. At the end of the course, all animals were completely and similarly treated and 48 hours after the last training session, anesthetized and sacrificed. After cardiac out and homogenization, the concentration of BAX, Bcl-2 and Caspase 3 was measured individually.

Results: After induction of diabetes, the concentration of BAX and Caspase- 3 significantly increased compared with healthy controls, while BCL-2 concentration decreased significantly. However, only exercise interaction and resveratrol had significant effect on BAX concentration and had no significant effect on Caspase-3 levels. Each exercise and resveratrol separately increased BCL-2 concentration, but their interactive effect was not significant.

Conclusion: Aerobic exercise and resveratrol have a beneficial effect on cardiac apoptosis in inducing diabetes, but their interaction is not significant in the process of cardiac apoptosis. Of course, aerobic exercise and resveratrol could be used as complementary therapies for myocardial protection against invasive apoptosis induced by diabetes.
\end{abstract}

Keywords: Diabetes mellitus, Resveratrol, Aerobic exercise, BAX, Bcl-2, Caspase3.

Cited as: Mehri A, Hosseinpour Delaware S, Azizi M, Azarbaijani MA, Farzangi P. The effect of aerobic training and resveratrol on some regulatory and executive factors of cardiomyocytes apoptosis in STZ-diabetic male rats. Medical Science Journal of Islamic Azad University, Tehran Medical Branch 2020; 30(1): 59-66.

Correspondence to: Sedigheh Hosseinpour Delaware

Tel: +989188335826

E-mail: delavar2009@iauksh.ac.ir

ORCID ID: 0000-0002-8589-1337

Received: 13 Jan 2019; Accepted: 2 Jul 2019 
مجله علوم يزشكى دانشكاه آزاد اسلامى

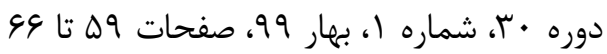

Original

Article

\section{اثر تمرين هوازى و رزوراترول بر برخى از فاكتورهاى تنظيمى و اجرايى آيويتوز كارديوميوسيتى در رتهاى نر ديابتى شده با STZ}

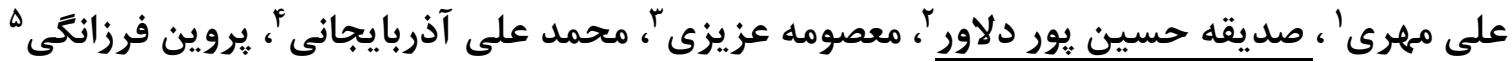

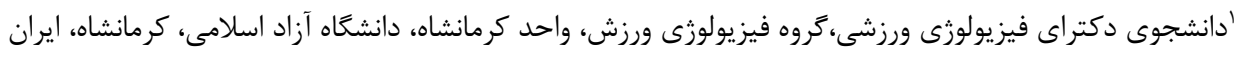

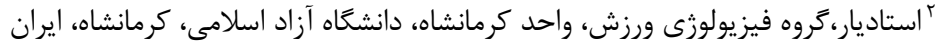

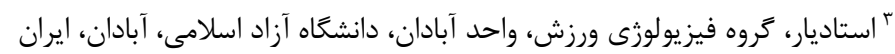

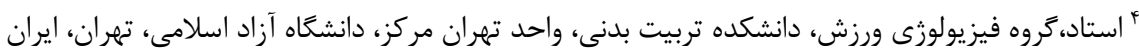

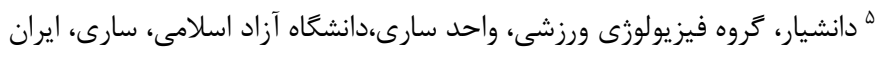
جـكيده

سابقه و هدف: هدف مطالعه حاضر /ثر تمرين هوازى به همراه مصرف مكمل رزوراترول بر فاكتورهاى تنظيمى و اجرايى آبويتوز

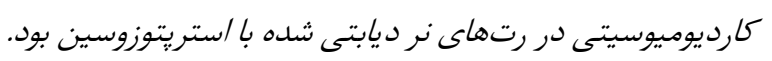

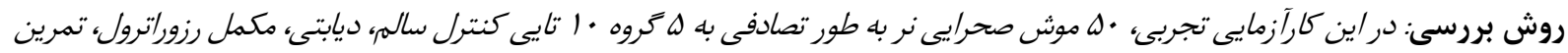

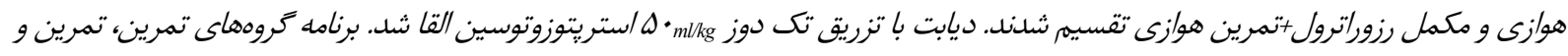

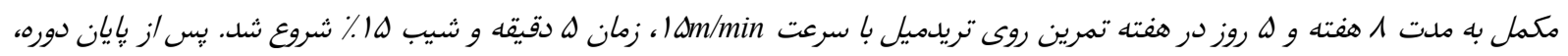

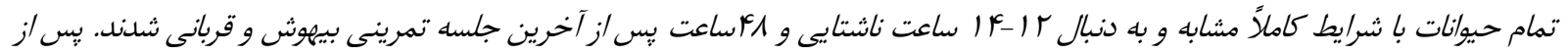

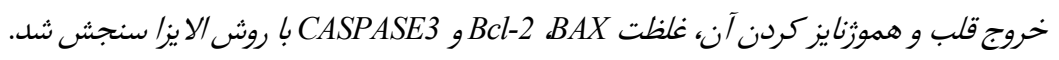

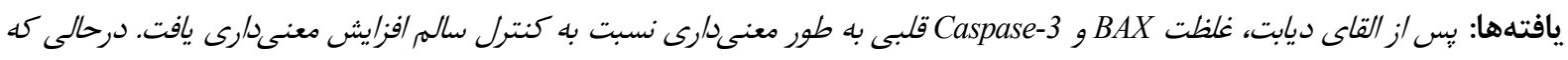

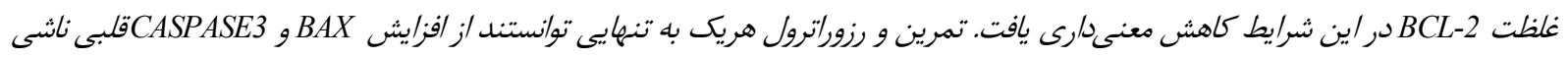

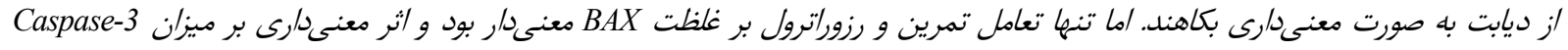

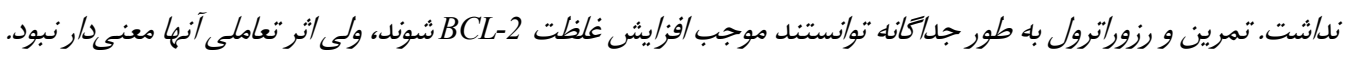

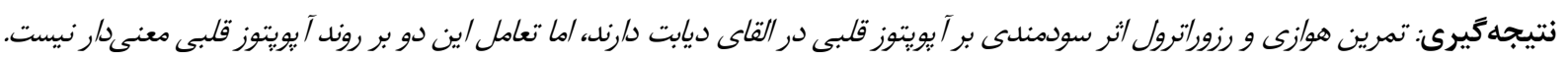

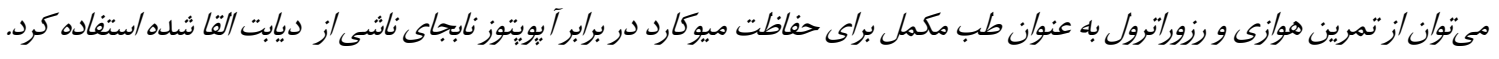

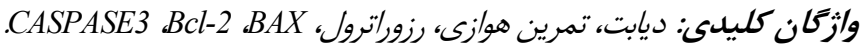

بيمارى رو به افزايش است، به طورى كه تعداد مبتلايـان از مقدمه

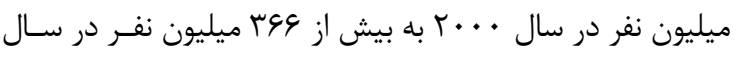

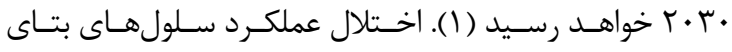

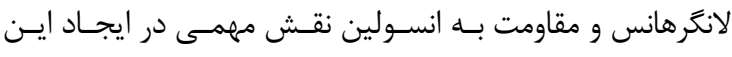

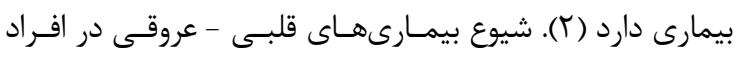

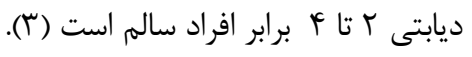
ديابت به عنوان يكى از شايعترين بيمارىهـاى مـزمن و از علـل اصلى مرك ومير در سراسر جهان شناخته شده است. شيوع ايـن فئن

آدرس نويسنده مسئول: كرمانشاه، دانشكاه آزاد اسلامى واحد كرمانشاه كـروه فيزيولـوزى ورزش، صـديقه :

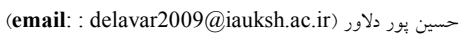
ORCID ID: 0000-0002-8589-1337 تاريخ دريافت مقاله: تاريخ بذيرش مقاله: 
رزوراترول در محافظت از قلب و عـروق و تـاثير احتمـالى آن بـر

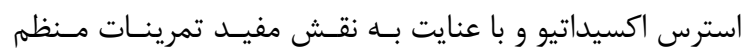

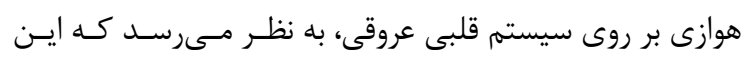

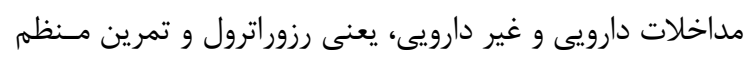

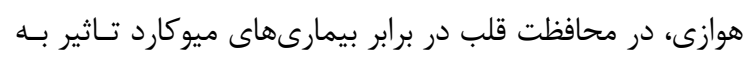

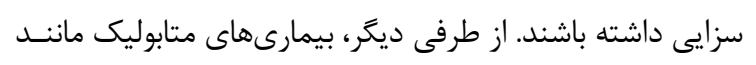

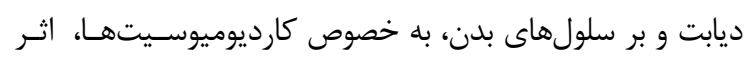

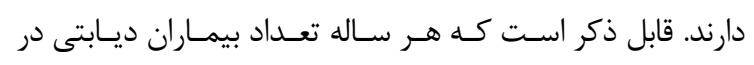

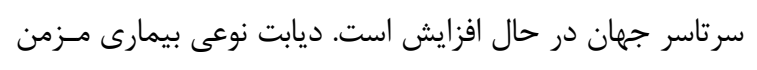

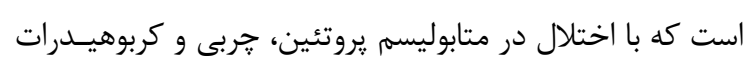

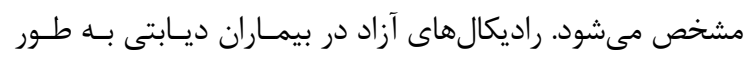

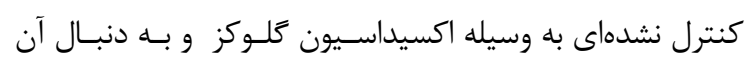

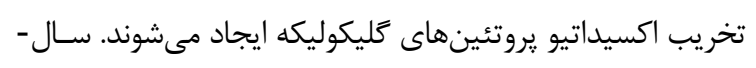

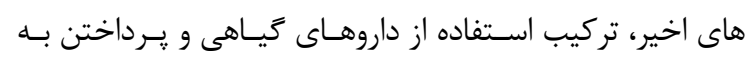

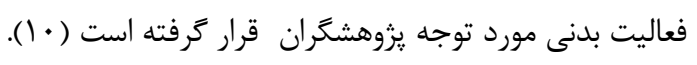

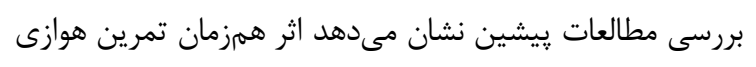

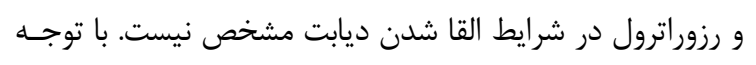

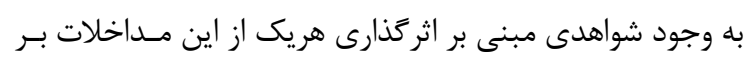

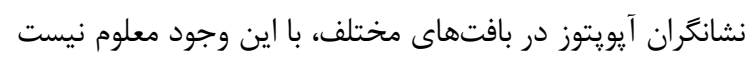

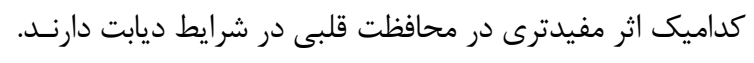

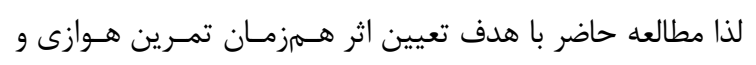

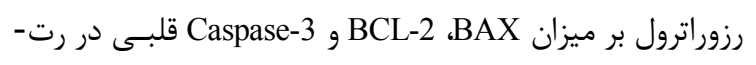
هاى ديابتى شده با استريتوزوسين انجام شد.

\section{مواد و روشها}

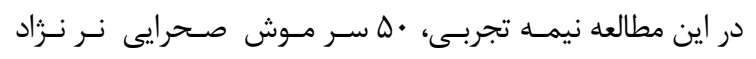

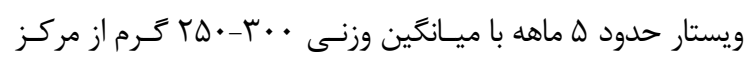

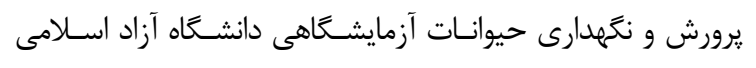

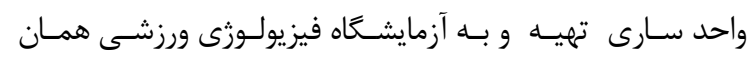

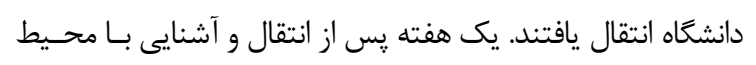

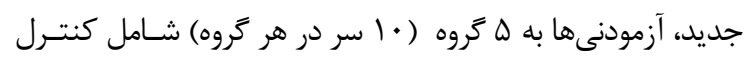

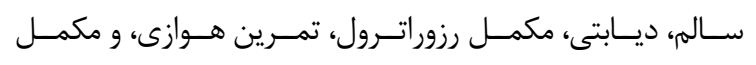

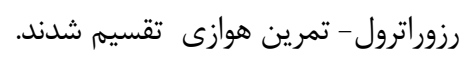

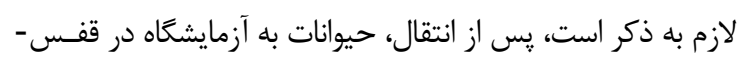

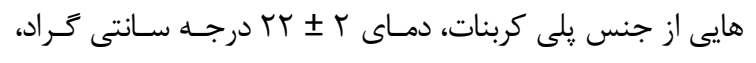

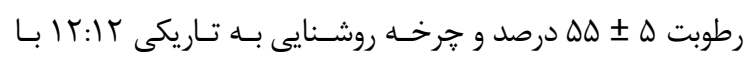

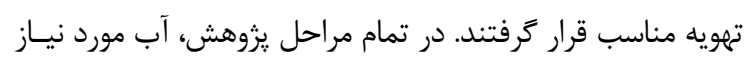

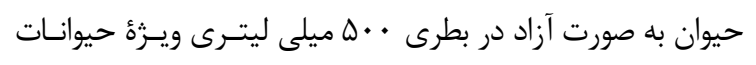

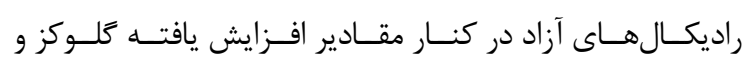

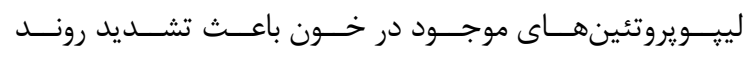

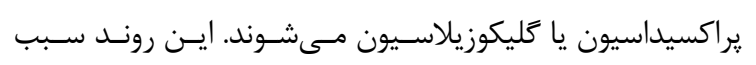

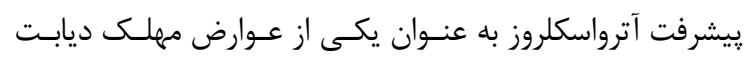

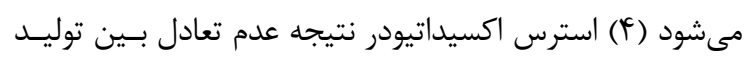

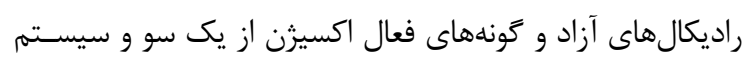

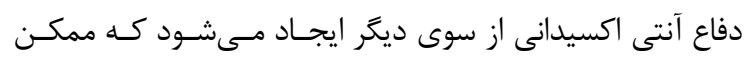

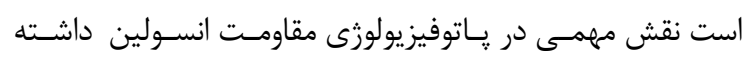

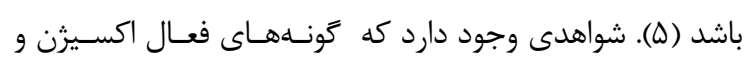

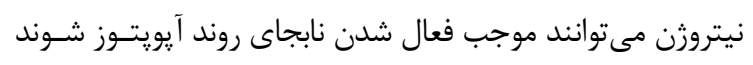

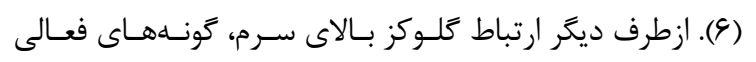

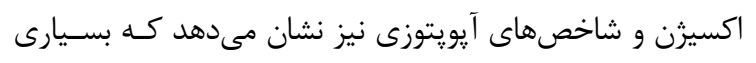

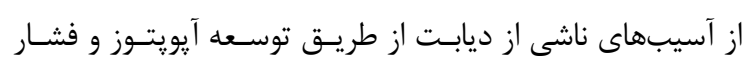

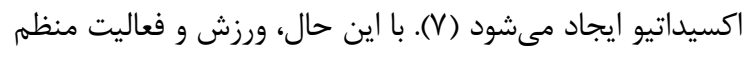

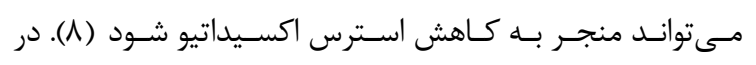

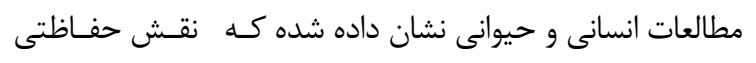

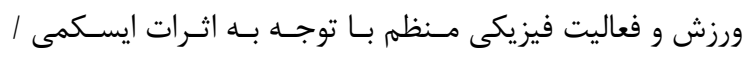

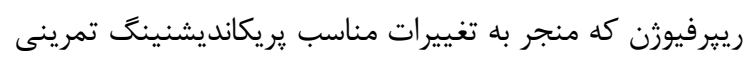

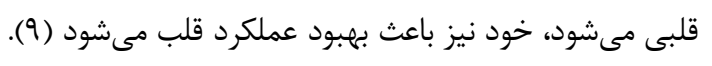

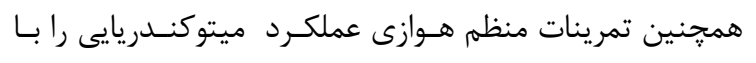

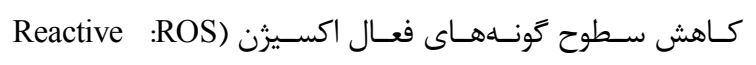
بxygen Species

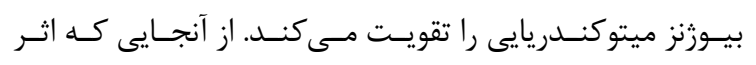

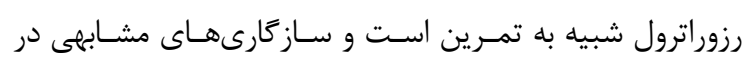

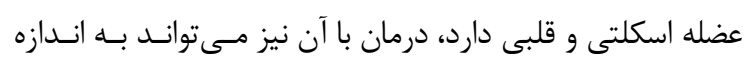
تمـرين ورزشـى در درمـان نارسـايى قلبـى مفيــد باشـــ (• (1).

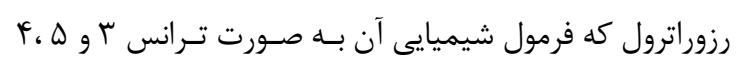

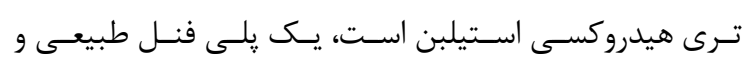

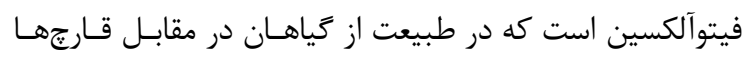

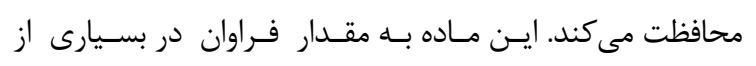

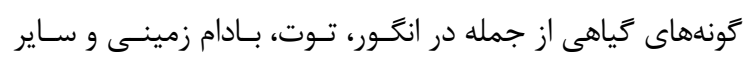

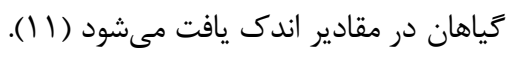

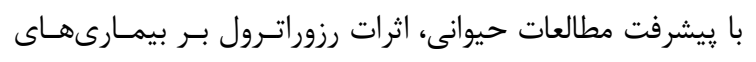

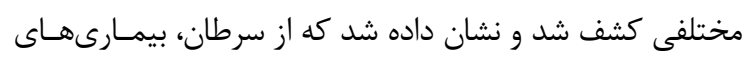

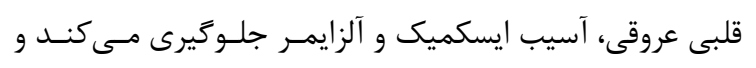

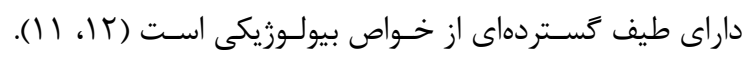

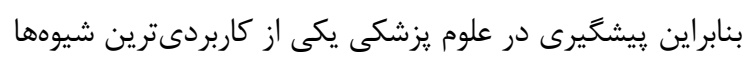

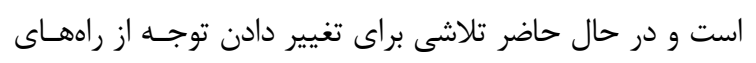

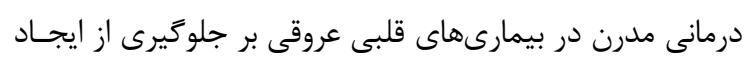

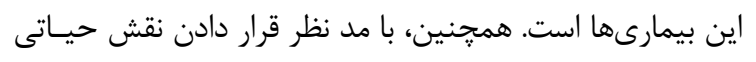




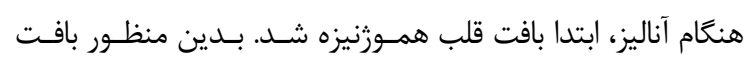

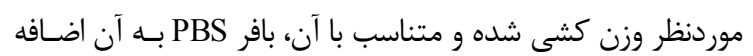

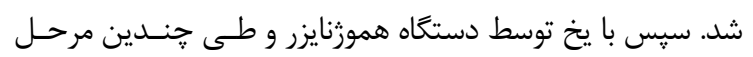

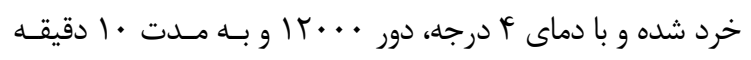

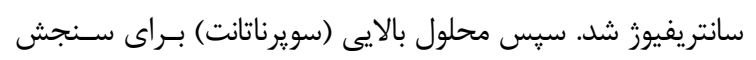
متغيرها مورد استفاده قرار زرفت.

سنجش هاى بيوشيميايى سطوح BCL2 و Bax با استفاده از كيتهاى تجارى ويـزّه سـاخت

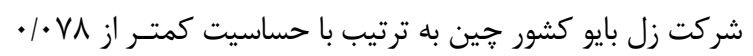

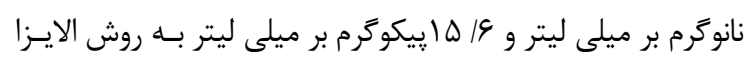

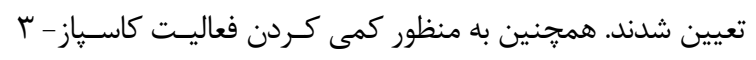

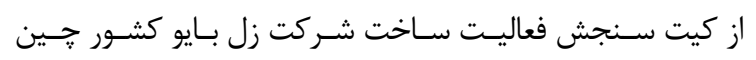
استفاده شد.

\section{روشهاى آمارى}

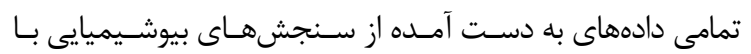

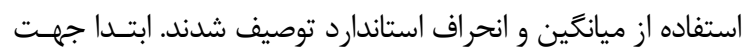

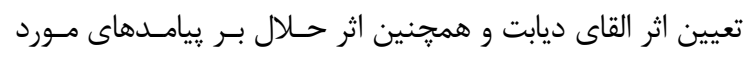

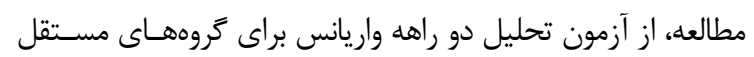

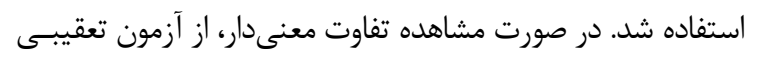

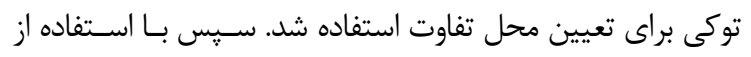

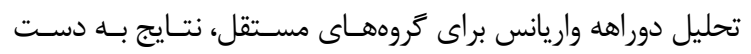

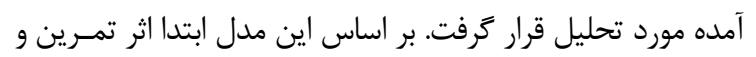

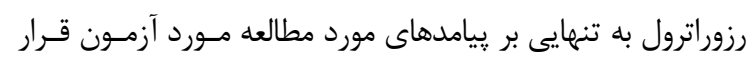

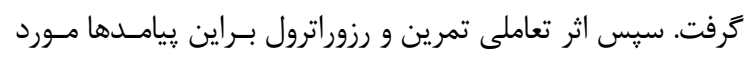

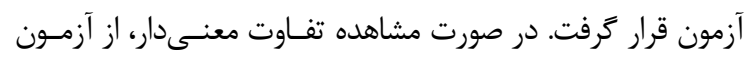

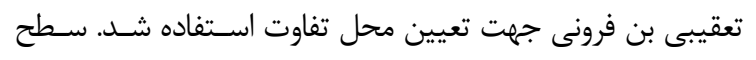

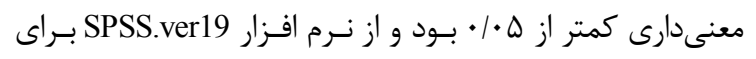
تحليل دادهها استفاده شد.

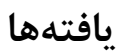

در اين مطالعه نيمه تجربى، •و سر موش صحرايى نر نزاد

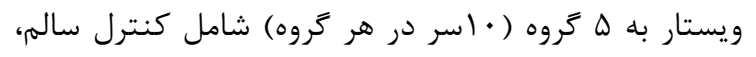

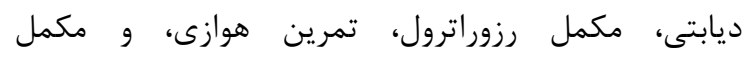
رزوراترول - تمرين هوازى تقسيم شدند.

نتايج القاى بيمارى ديابت و مقايسه ميانگين قند خون خون

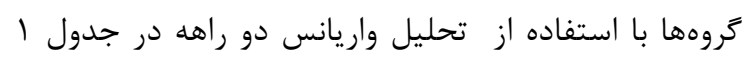

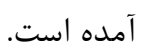

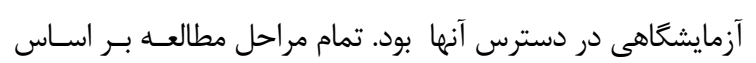

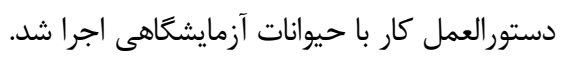
القاى ديابت براى ديابتى كردن موشهــا از استريتوزوسـين (STZ) بـهـ صـورت

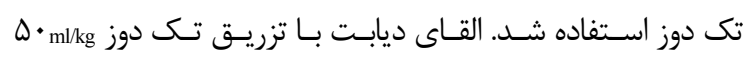

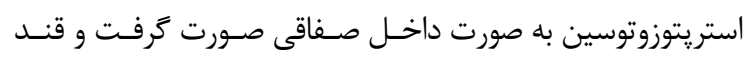

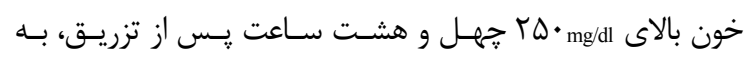

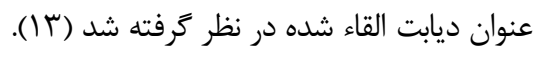
برنامه تمرين هوازى

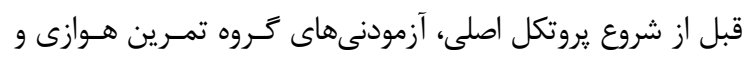

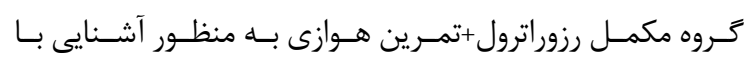

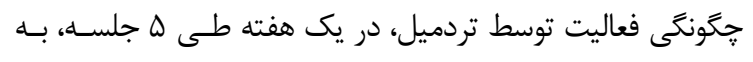

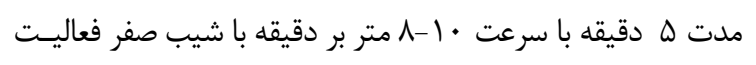

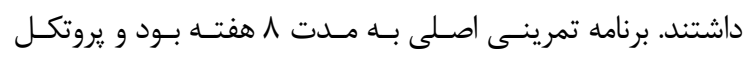

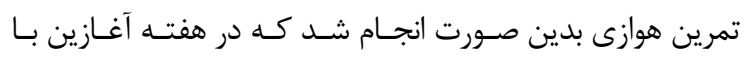

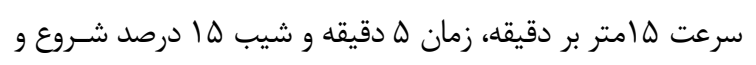

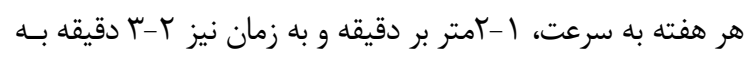

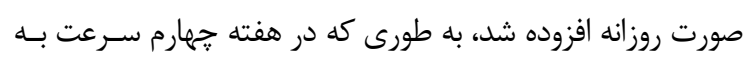

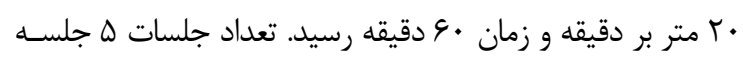

در هفته بود (If). (If).

\section{مكمل رزوراترول}

مكمل رزوراترول بر اساس مطالعات ييشين تهيه شد. براى هر بـار

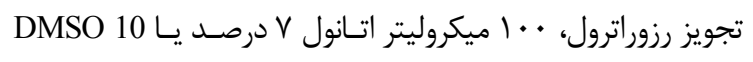

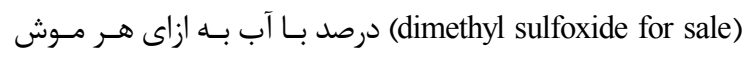

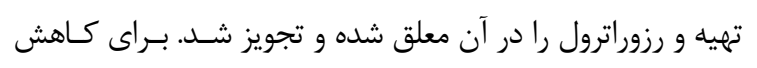

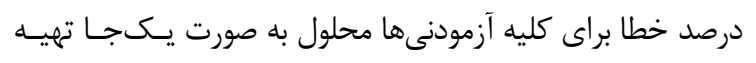

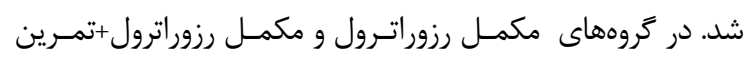

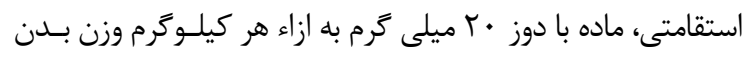

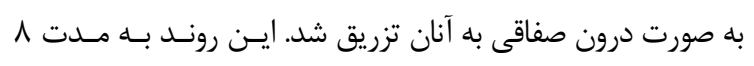
هفته انجام گرفت (ه (1).

\section{نحوه قربانى كردن حيوانات و بافت بردارى}

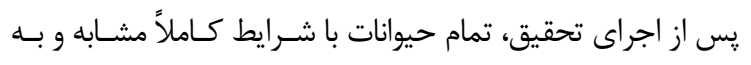

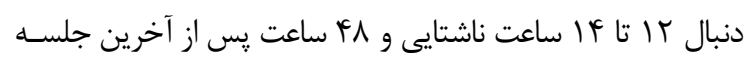
تمرينى و تزريقات، با تزريق داخل صفاقى كتامين ( •و ميلى كرم

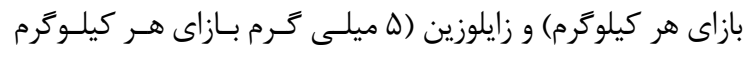

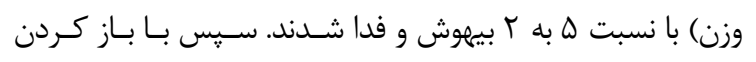

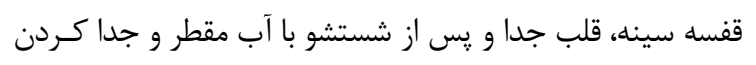

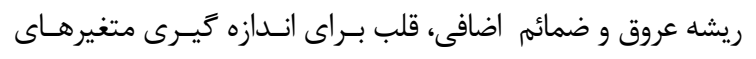

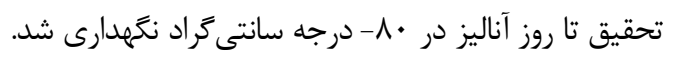


القاى ديابت موجب افزايش معنى دار غلظت CASPASE-3

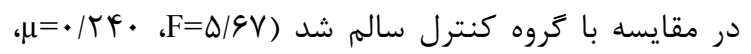

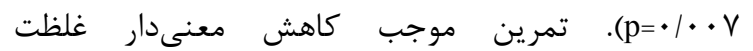
CASPASE3

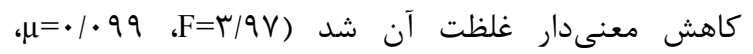

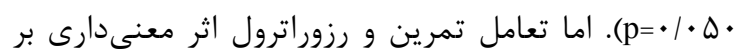

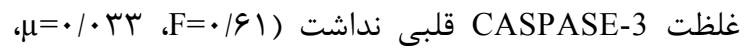

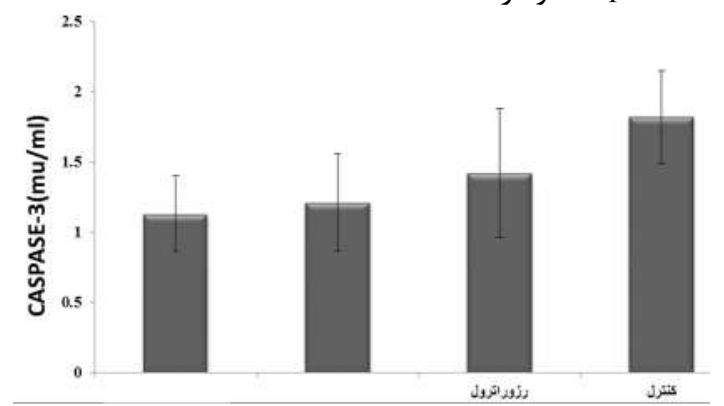
نمودار Гَ. غلظت CASPASE-3 قلبى در كروههاى مورد مطالعه شامل كروه كنترل، رزوراترول، ورزش هوازى و ورزش هوازى مزوراترول

\section{بحث}

مطالعه حاضر نشان داد كه ورزش هوازى و مكمل رزوراترول

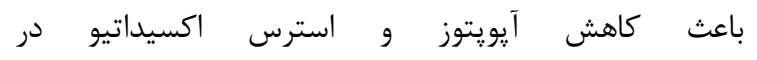
كارديوميوسيتهاى موش صحرايى ديابتى مىشود. علاوه بر

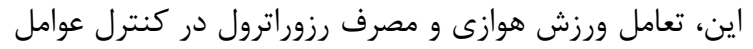
مؤثر آيويتوز و آنزيمهاى استرس اكسيداتيو كارديوميوسيتها ونها در موشهاى صحرايى نر ديابتى تاثير بيشترى داشته است. شيوع بيمارىهاى قلبى عروقى در بيماران ديابتى ك تأ أ برابر

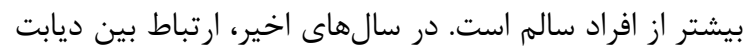

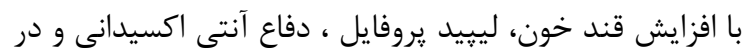
نتيجه افزايش واكنشهاى اكسيداتيو به طور كستردهاى مورد بررسى قرار كرفته است. نتايج مطالعات نشان داده است كه

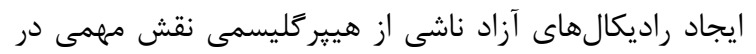
ياتوزنز و يیشرفت عوارض اين بيمارى دارد (ع) (1).

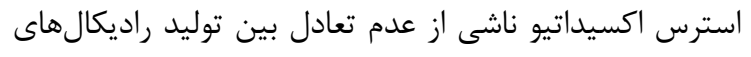

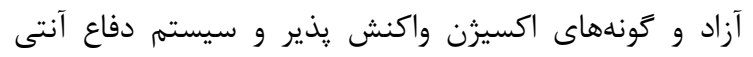

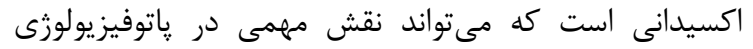

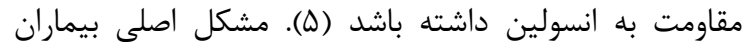

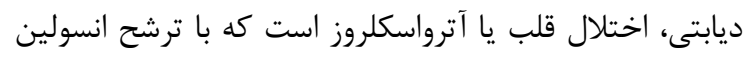
نامناسب و مقاومت به انسولين ارتباط دارد ( ( IV-).

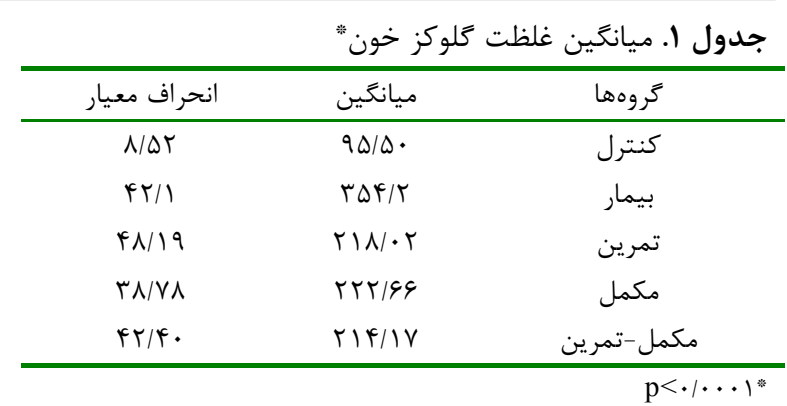

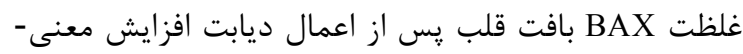

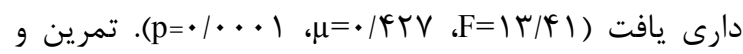
رزوراترول توانستند موجب كاهش غلظت BAX قلبى شوند.

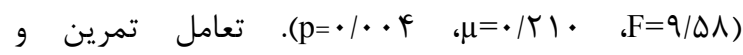
رزوراترول نيز موجب كاهش معنىدار BAX شد (F=F/qV)،

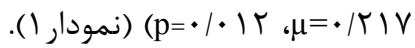

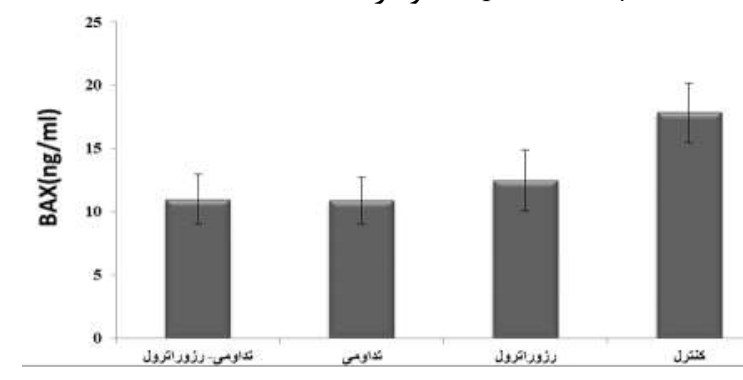
نمودار 1. غلظت BAX قلبى در كروههاى مورد مطالعه شامل كروه كنترل، رزوراترول، ورزش هوازى و ورزش هوازى كـر كزوراترول

غلظت BCl-2 در اثر ديابت كاهش معنىدارى يافت هم $\mathrm{F}=\mathcal{N} / \mathrm{F} T)$ رزوراترول توانستند درگروه ديابتى موجب افزايش غلظت

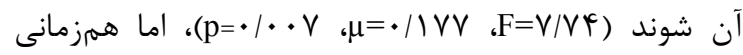
تمرين و رزوراترول بر غلظت BCL-2 اثر معنىدارى نداشت

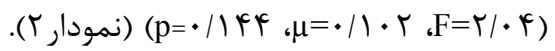

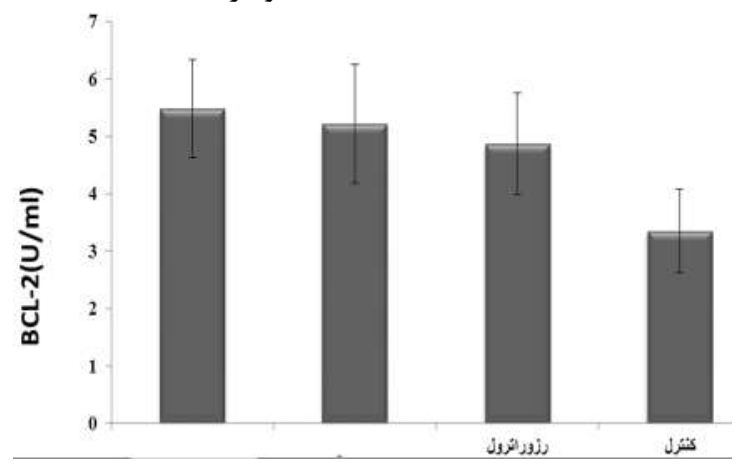

نمودار r. غ غلظتBCL-2 قلبى در كروههاى مورد مطالعه شامل

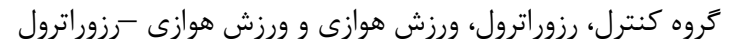




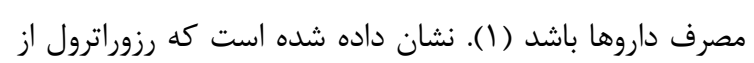
طريق فعال سازى p38 در برابر القاء

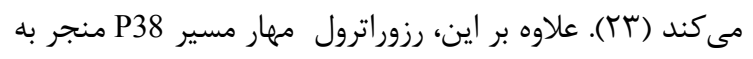

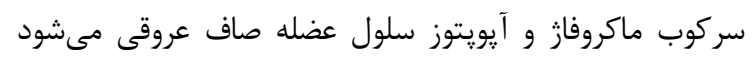

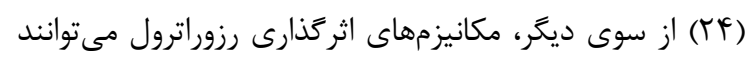

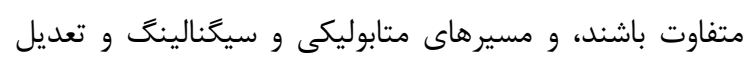

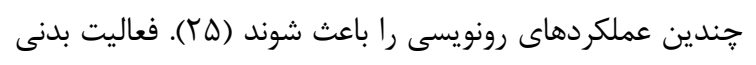

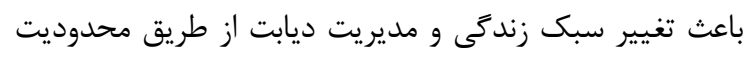

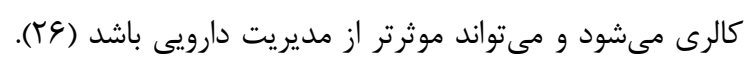

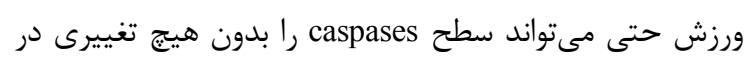

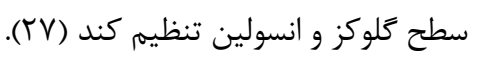

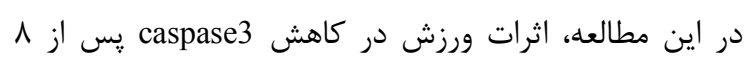

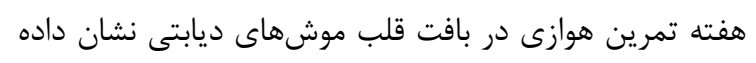

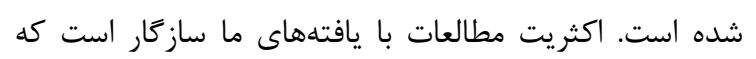

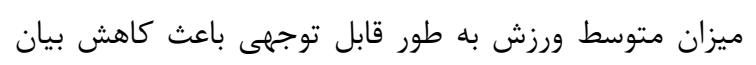
caspase3

$$
\text { كنترل آيويتوز سلولى دارد (T) (T). }
$$

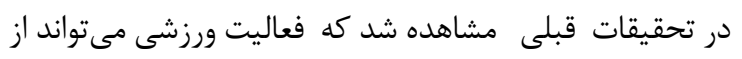

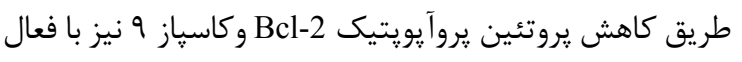

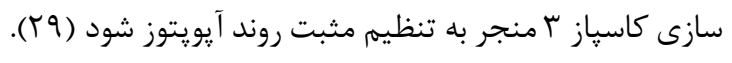

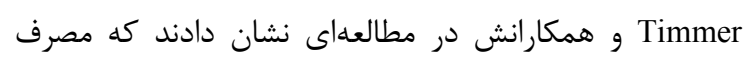

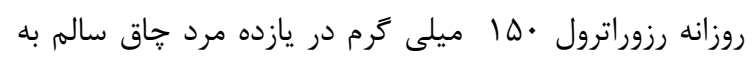

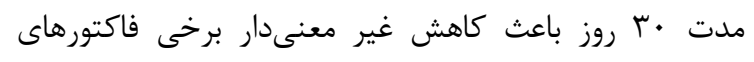

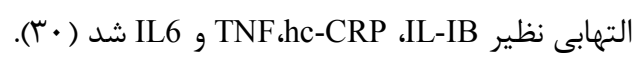

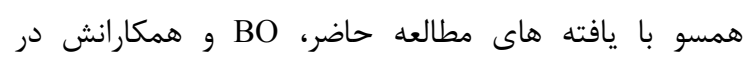

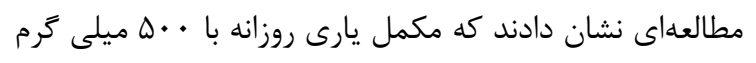

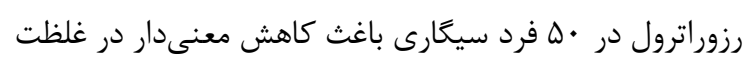
hs-CRP

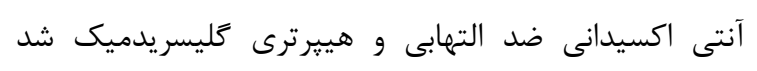

سيو و همكارانش نيز نشان دادند كه تمرين استقامتى، بيان

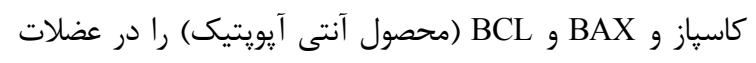

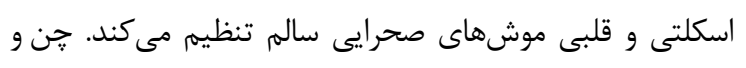

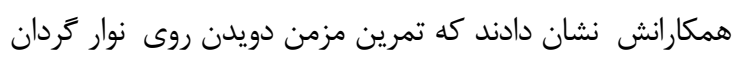

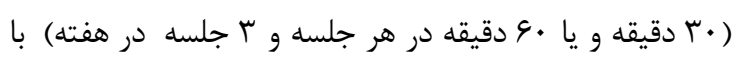

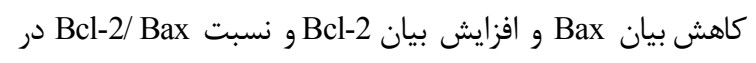

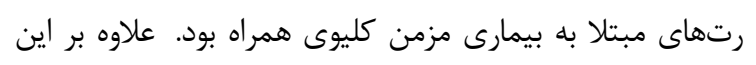

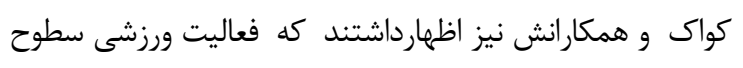

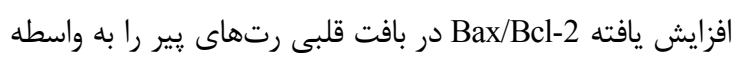

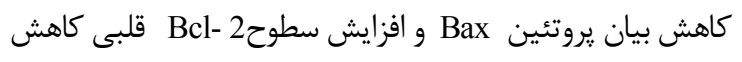

محققان كزارش كردهاند كه فعاليت ورزشى متوسط مئونواند

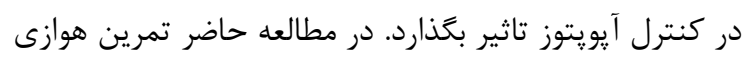
توانست سطح BAX و Bcl2 را تنظيم كند كه با نتايج

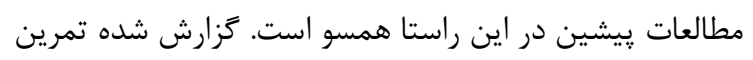

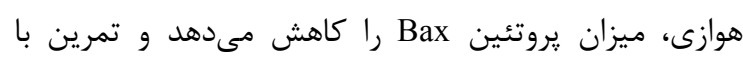

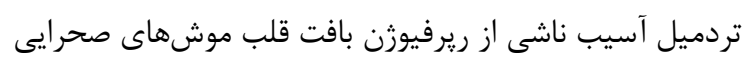
را تنظيم مى كند (·) (1). مطالعات نشان داده رزوراترول مجموعهاى از اثرات مات مستقيم

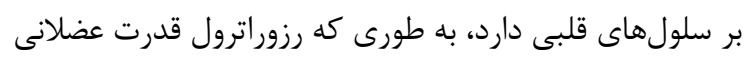

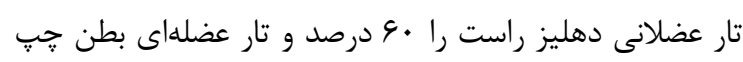

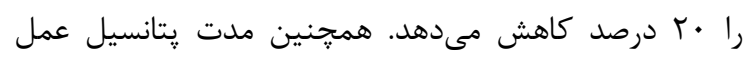

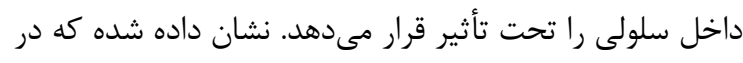

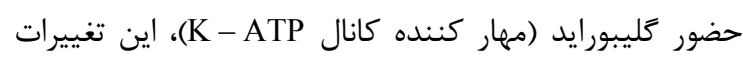
ناشى از رزوراترول به شدت كاهش مئ ميابد (· (Y).

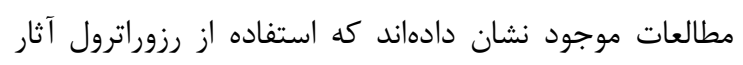

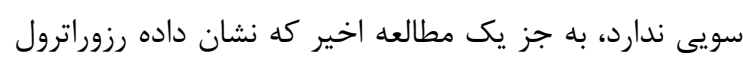

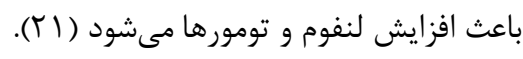

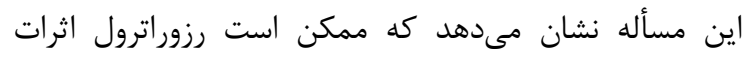

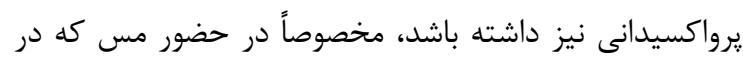

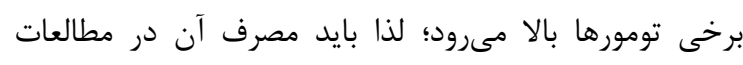
انسانى با احتياط صورت كيرد.

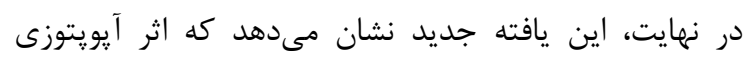

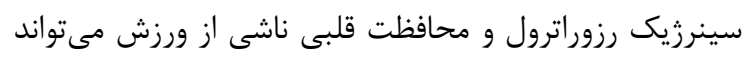

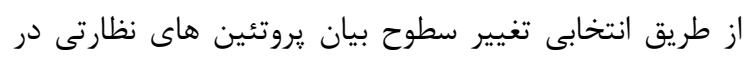

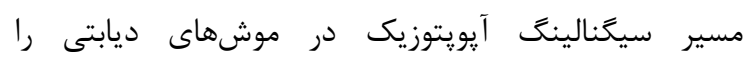
ميانجيكرى كند.

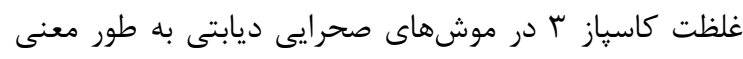

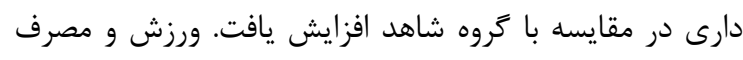

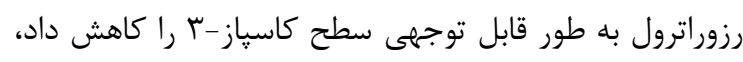

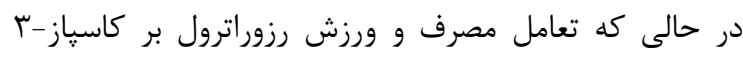

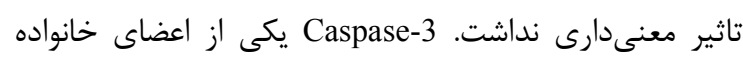

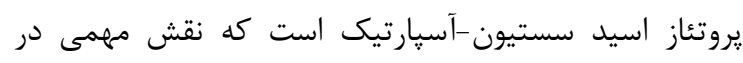
آيويتوز سلولى دارد. سيخنال آيويتوزى با فعال سازى كاسيازها (به عنوان مثال و و -7 caspase-3

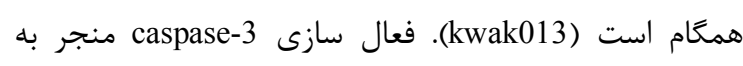

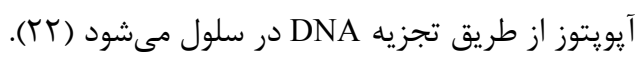

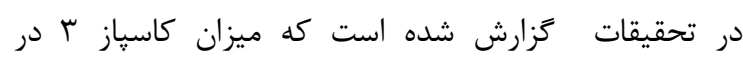

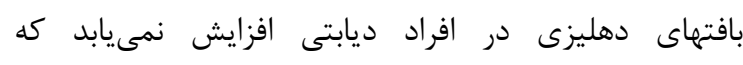

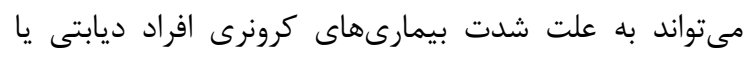




$$
\begin{aligned}
& \text { مطالعات بيشترى به ويزه با دوزهاى متفاوت رزوراترول براى } \\
& \text { درك بهتر اثرگذارى اين دو مداخله است. } \\
& \text { تقدير و تشكر }
\end{aligned}
$$

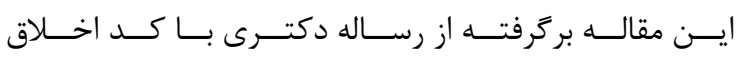

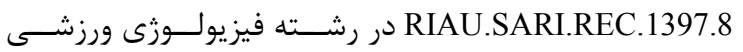

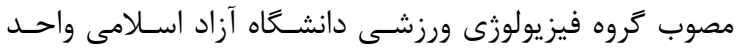

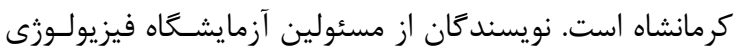

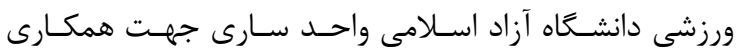

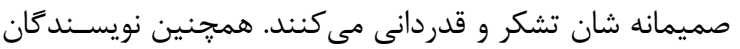

$$
\begin{aligned}
& \text { عدم تعارض منافع را اعلام مى دارند. }
\end{aligned}
$$

\section{REFERENCES}

$$
\begin{aligned}
& \text { مى دهد (Tr) كه اين مسئله تاييد ديخرى بر نقش حمايتى فعاليت } \\
& \text { ورزشى از طريق كاهش روند آيويتوز در بافتهاى بدن است. }
\end{aligned}
$$

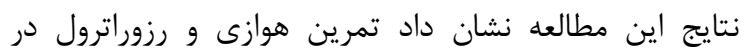

$$
\begin{aligned}
& \text { شرايط ديابت القا شده با STZ اثر مطلوبى بر نشانكران }
\end{aligned}
$$

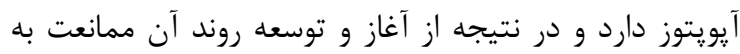

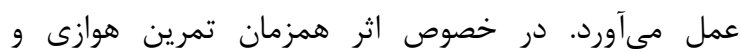

$$
\begin{aligned}
& \text { رزوراترول، ياسخ نشانكران آيويتوز يكسان نبود و غلظت آنزيم } \\
& \text { CASPASE-3 تحت تاثير همزمان اين دومداخله قرار نخرفت. } \\
& \text { با اين وجود مشخص شد كه اين دو مداخله با اثر گذارى بر } \\
& \text { نشانكران آيويتوز اثر محافظتى خود را بر بافت قلب در شرايط } \\
& \text { ديابت القا شده اعمال مى كنند. براين اساس توصيه مىشورد در } \\
& \text { اين شرايط از اين دو مداخله براى محافظت قلب از آسيبهاى } \\
& \text { ناشى از ديابت استفاده شود. با اين حال، باز هم نياز به }
\end{aligned}
$$

1. Anderson EJ, Rodriguez E, Anderson CA, Thayne K, Chitwood WR, Kypson AP. Increased propensity for cell death in diabetic human heart is mediated by mitochondrial-dependent pathways. Am J Physiol Heart Circ Physiol 2010;300:H118-24.

2.Chao M, Zou D, Zhang Y, Chen Y, Wang M, Wu H, Ning G, Wang W. Improving insulin resistance with traditional Chinese medicine in type 2 diabetic patients. Endocrine 2009;36:268-74.

3.Mirfeizi M, Mehdizadeh Tourzani Z, Mirfeizi SZ, Asghari Jafarabadi M, Rezvani HR, Afzali M. Controlling type 2 diabetes mellitus with herbal medicines: a triple-blind randomized clinical trial of efficacy and safety. J Diabetes. 2016;8:647-56.

4.Sanders RA, Rauscher FM, Watkins III JB. Effects of quercetin on antioxidant defense in streptozotocin-induced diabetic rats. J Biochem Mol Toxicol 2001;15:143-9.

5.Sadi G, Kartal Dİ, Güray T. Regulation of glutathione S-transferase Mu with type 1 diabetes and its regulation with antioxidants. Turk J Biochem 2013; $38 ; 92-100$.

6.Ryter SW, Kim HP, Hoetzel A, Park JW, Nakahira K, Wang X, et al. Mechanisms of cell death in oxidative stress. Antioxid Redox Sign 2007;9:49-89.

7.Sha J, Sui B, Su X, Meng Q, Zhang C. Alteration of oxidative stress and inflammatory cytokines induces apoptosis in diabetic nephropathy. Mol Med Rep 2017;16:7715-23.

8.Maybaum S, Ilan M, Mogilevsky J, Tzivoni D. Improvement in ischemic parameters during repeated exercise testing: a possible model for myocardial preconditioning. Am J Cardiol 1996;78:1087-91.

9.Shave R, Dawson E, Whyte G, George K, Gaze D, Collinson P. Altered cardiac function and minimal cardiac damage during prolonged exercise. Med Sci Sport Exer 2004;36:1098-103.

10.Dolinsky VW, Rogan KJ, Sung MM, Zordoky BN, Haykowsky MJ, Young Meet al. Both aerobic exercise and resveratrol supplementation attenuate doxorubicin-induced cardiac injury in mice. Am $J$ Physiol Endoc $M$ 2013;305:E243-53.

11.Das S, Alagappan VK, Bagchi D, Sharma HS, Maulik N, Das DK. Coordinated induction of iNOS-VEGF-KDReNOS after resveratrol consumption: A potential mechanism for resveratrol preconditioning of the heart. Vas Pharmacol 2005;42:281-9.

12.Lee PS, Chiou YS, Ho CT, Pan MH. Chemoprevention by resveratrol and pterostilbene: Targeting on epigenetic regulation. Biofactors 2018;44:26-35

13.Moeini Fard, M, Hedayati, M. Alloxan and streptozotocin, diabetes research tool. Applied Sport Physiology Research 2014;10(20):13-22. [In Persian]

14.Linden MA, Fletcher JA, Morris EM, Meers GM, Laughlin MH, Booth FW, et al. Treating NAFLD in OLETF rats with vigorous-intensity interval exercise training. Med Sci Sports Exerc 2015;47:556-58. 
15.Shankar S, Singh G, Srivastava RK. Chemoprevention by resveratrol: molecular mechanisms and therapeutic potential. Front Biosci 2007;12:4839-54.

16.Torres M, Canal J, Perez C. Oxidative stress in normal and diabetic rats. Physiol Res 1999;48:203-208.

17.Pérez-Gallardo RV, Noriega-Cisneros R, Esquivel-Gutiérrez E, Calderón-Cortés E, Cortés-Rojo C, Manzo-Avalos S, et al. Effects of diabetes on oxidative and nitrosative stress in kidney mitochondria from aged rats. $\mathrm{J}$ Bioenerg Biomembr 2014;46:511-8.

18.Dehghan F, Soori R, Gholami K, Abolmaesoomi M, Yusof A, Muniandy Set al. Purslane (Portulaca oleracea) seed consumption and aerobic training improves biomarkers associated with atherosclerosis in women with type 2 diabetes (T2D). Sci Rep 2016;6:37819.

19.Fadini GP, Iori E, Marescotti MC, de Kreutzenberg SV, Avogaro A. Insulin-induced glucose control improves HDL cholesterol levels but not reverse cholesterol transport in type 2 diabetic patients. Atherosclerosis 2014;235:415-17.

20.Buluc M, Ayaz M, Turan B, Demirel-Yilmaz E. Resveratrol-induced depression of the mechanical and electrical activities of the rat heart is reversed by glyburide: evidence for possible K ATP channels activation. Arch Pharm Res 2007;30:603-7.

21.Smoliga JM, Baur JA, Hausenblas HA. Resveratrol and health-a comprehensive review of human clinical trials. Mol Nutr Food Res 2011;55:1129-41.

22.Arbab-Zadeh A, Dijk E, Prasad A, Fu Q, Torres P, Zhang R, et al. Effect of aging and physical activity on left ventricular compliance. Circulation 2004;110:1799-805.

23.Ulakcsai Z, Bagaméry F, Vincze I, Szökö É, Tábi T. Protective effect of resveratrol against caspase 3 activation in primary mouse fibroblasts. Croat Med J 2015;56:78-84.

24.Guo R, Li W, Liu B, Li S, Zhang B, Xu Y. Resveratrol protects vascular smooth muscle cells against high glucoseinduced oxidative stress and cell proliferation in vitro. Med Sci Monit Basic Res 2014;20:82.

25.Khan RS, Fonseca-Kelly Z, Callinan C, Zuo L, Sachdeva MM, Shindler KS. SIRT1 activating compounds reduce oxidative stress and prevent cell death in neuronal cells. Front Cell Neurosci 2012; 31;6:63.

26.Knowler WC, Barrett-Connor E, Fowler SE, Hamman RF, Lachin JM, Walker EA, et al. Reduction in the incidence of type 2 diabetes with lifestyle intervention or metformin. N Engl J Med 2002;346:393-403.

27.Moien-Afshari F, Ghosh S, Khazaei M, Kieffer TJ, Brownsey RW, Laher I. Exercise restores endothelial function independently of weight loss or hyperglycaemic status in $\mathrm{db} / \mathrm{db}$ mice. Diabetologia. 2008;51:1327-37.

28.Ghosh S, Khazaei M, Moien-Afshari F, Ang LS, Granville DJ, Verchere CB, et al. Moderate exercise attenuates caspase- 3 activity, oxidative stress, and inhibits progression of diabetic renal disease in $\mathrm{db} / \mathrm{db}$ mice. Am J Physiol Renal Physiol 2009;296:F700-8.

29.Hong J-H, Kim M-J, Park M-R, Kwag O-G, Lee I-S, Byun BH, et al. Effects of vitamin streptozotocin-induced diabetic rats. Clinica chimica acta on oxidative stress and membrane fluidity in brain. Am J Physiol Renal Physiol 2004; 340:107-15.

30.Timmers S, Konings E, Bilet L, Houtkooper RH, van de Weijer T, Goossens GHet al. Calorie restriction-like effects of 30 days of resveratrol supplementation on energy metabolism and metabolic profile in obese humans. Cell Metabol 2011;14:612-22.

31.Bo S, Ciccone G, Castiglione A, Gambino R, De Michieli F, Villois P, et al. Anti-inflammatory and antioxidant effects of resveratrol in healthy smokers a randomized, double-blind, placebo-controlled, cross-over trial. Curr Med Chem 2013;20:1323-31.

32.Kwak HB. Effects of aging and exercise training on apoptosis in the heart. J Exerc Rehabil 2013;9:212. 